\title{
Endoscopic endonasal transpterygoid transnasopharyngeal management of petroclival chondrosarcomas without medial extension
}

\author{
Gautam U. Mehta, MD, ${ }^{1}$ Franco DeMonte, MD, ${ }^{1}$ Shirley Y. Su, MBBS, ${ }^{2}$ Michael E. Kupferman, MD, ${ }^{2}$ \\ Ehab Y. Hanna, MD, ${ }^{2}$ and Shaan M. Raza, MD'

\begin{abstract}
${ }^{1}$ Department of Neurosurgery, and ${ }^{2} \mathrm{Head}$ and Neck Surgery, The University of Texas M.D. Anderson Cancer Center, Houston, Texas
\end{abstract}

\begin{abstract}
Chondrosarcomas of the skull base are malignant tumors for which surgery is the primary therapeutic option. Gross-total resection has been demonstrated to improve survival in patients with these tumors. Chondrosarcomas arising from the petroclival synchondrosis harbor particularly unique anatomical considerations that have long been a barrier to achieving such a resection. Endoscopic endonasal transpterygoid approaches have been recently used to gain improved access to such lesions; however, these approaches have classically relied on a medial to lateral transclival trajectory, which provides limited exposure for complete resection of lateral disease. In this paper the authors describe an endoscopic endonasal transpterygoid transnasopharyngeal approach that provides comprehensive access to the petroclival region through dissection of the eustachian tube with resection of the cartilaginous torus tubarius. Of note, the authors have previously demonstrated the superior outcomes and validity of this approach relative to other cranial base techniques for petroclival chondrosarcomas. Surgical outcomes in 5 cases of chondrosarcoma without medial extension are detailed. Gross-total resection was achieved in 4 of 5 patients. Postoperative complications included transient palatal numbness in all patients and eustachian tube dysfunction due to the approach. With tympanostomy tube placement, no patient had persistent hearing loss. Overall, this approach appears to be a safe and effective technique for resection of petroclival chondrosarcomas.
\end{abstract}

https://thejns.org/doi/abs/10.3171/2018.3.JNS172722

KEYWORDS chondrosarcoma; endoscopic endonasal approach; petroclival; transpterygoid; skull base; surgical technique

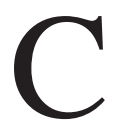

HONDROSARCOMAS are malignant tumors whose behavior can range from indolent to locally aggressive tumors prone to systemic recurrence. While histology-based grading systems are strongly predictive of prognosis, ${ }^{4,12,18}$ data specific to skull base chondrosarcomas underscore the importance of achieving a gross-total resection of involved bone along with extracompartmental (extraosseous) disease beyond the skull base. Such a resection has been shown to significantly impact progressionfree survival. $3,16,18,19,23$

The site of origin of chondrosarcomas has been demonstrated to be an important factor affecting resection rates and neurological outcomes and in determining approach selection. ${ }^{17}$ Petroclival synchondrosis chondrosarcomas have unique anatomical challenges that must be considered in achieving an oncological resection. A succession of surgical approaches from open lateral approaches to endoscopic approaches have been described to address these challenges. ${ }^{1,7,13,14,17,19-21,23,25}$

Endoscopic endonasal approaches with transclival and transpterygoid modifications have been proposed for petrous lesions and have particular applicability to petroclival chondrosarcomas. All reported strategies thus far rely on the presence of medial disease extension into the clivus. ${ }^{13,14,22}$ Additionally, recognizing that the petroclival synchondrosis extends from the inferior aspect of the foramen lacerum to the jugular foramen, the endoscopic strategies reported to date do not provide an ability to resect all

ABBREVIATIONS $C N=$ cranial nerve; ICA = internal carotid artery; IMA = internal maxillary artery; PPF = pterygopalatine fossa.

SUBMITTED November 5, 2017. ACCEPTED March 1, 2018.

INCLUDE WHEN CITING Published online August 3, 2018; DOI: 10.3171/2018.3.JNS172722. 
invaded bone around the petroclival synchondrosis while simultaneously addressing extracompartmental disease extension. ${ }^{13,14,22}$

Building on previous strategies, ${ }^{10,13,14,22,24}$ we report our surgical technique for managing petroclival chondrosarcomas maintaining the expectation of an oncologically complete resection without relying on the presence of medial clival disease extension. In a previous publication we demonstrated the superior oncological and functional outcomes achieved with this technique relative to other endoscopic and open skull base approaches in the management of petroclival chondrosarcomas. ${ }^{17}$

\section{Methods}

A retrospective review was performed of all surgically treated patients for histopathologically confirmed skull base chondrosarcomas between 1994 and 2017 at our institution, under an IRB-approved protocol. Fifty patients with the diagnosis of chondrosarcoma were treated surgically, of whom 15 underwent an endoscopic resection. Five patients (treated from 2014 to 2017) with petroclival chondrosarcomas without medial clival extension who solely underwent an endoscopic transpterygoid resection were included in this study. The technique used is reviewed and surgical results are reported.

All surgical strategies were designed with the intent of a safe gross-total resection of all bony skull base disease and extracompartmental extension. The description of the endoscopic endonasal transpterygoid approach (Video 1) is systematically divided into several steps: 1) sinonasal cavity dissection/medial maxillectomy, 2) pterygopalatine fossa dissection, 3) transpterygoid/medial infratemporal fossa dissection, 4) transclival dissection, 5) carotid artery skeletonization, 6) eustachian tube dissection, and 7) tumor resection and reconstruction.

VIDEO 1. Clip showing endoscopic endonasal transpterygoid transnasopharyngeal resection of a petroclival chondrosarcoma. Details of the technique are outlined in this video. Copyright Shaan M.

Raza. Published with permission. Click here to view.

The approach and resection are typically performed primarily with $0^{\circ}$ endoscopes, although angled $\left(30^{\circ}\right.$ and $\left.45^{\circ}\right)$ endoscopes may be needed toward the parts of the resection involving the jugular foramen.

\section{Sinonasal Cavity Dissection}

A maximally sized Hadad-Bassagasteguy flap is harvested contralateral to the tumor, in a fashion ensuring adequate coverage to the contralateral jugular foramen. This flap is stored within the maxillary sinus. On the ipsilateral side, anterior/posterior ethmoidectomies are completed along with resection of the lateral attachment of the middle turbinate, exposing the lamina papyracea. A middle turbinate resection is not required.

A wide medial maxillectomy is completed. The posterior aspect of the inferior turbinate is resected to allow sufficient access to the eustachian tube and working space along the low petroclival synchondrosis/jugular tubercle. The anterior aspect of the inferior turbinate is preserved to prevent nasolacrimal duct injury. A generous posterior septectomy is performed, followed by a sphenoidotomy
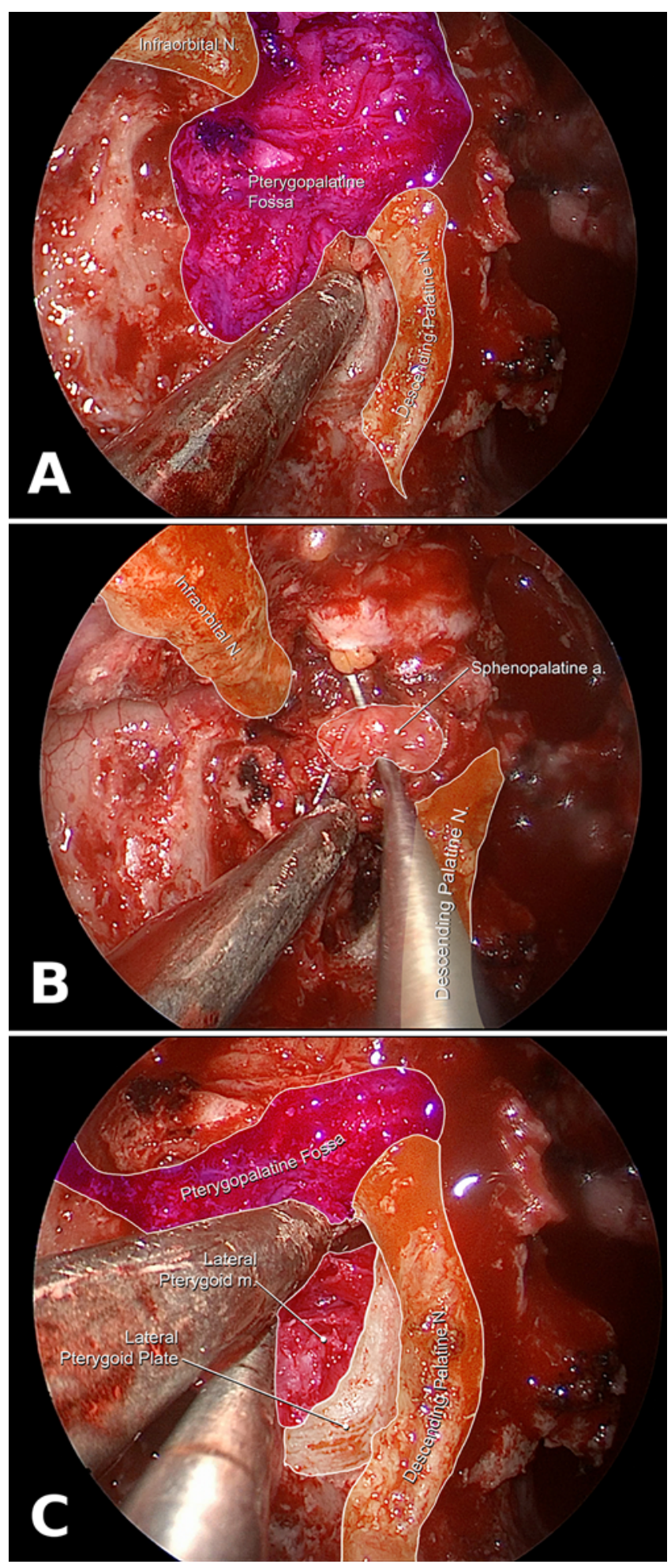

FIG. 1. PPF dissection. A: After completion of the medial maxillectomy, the posterior wall of the maxillary sinus is removed and the descending palatine nerve is fully skeletonized from its canal. B: The anterior periosteum of the PPF is sharply incised and the sphenopalatine artery is identified and clipped. C: This maneuver allows lateral mobilization of the bulk of the PPF in order to have greater working access to the medial infratemporal fossa. Images are depicted for an approach to the right petroclival synchondrosis. a. = artery; $m$. = muscle; N. = nerve. Figure is available in color online only. 
that extends laterally toward the ipsilateral vidian canal and requires sacrifice of the pharyngeal artery within the palatovaginal canal, just medial to the vidian canal.

\section{Pterygopalatine Fossa Dissection}

The pterygopalatine fossa (PPF) is exposed by removal of the ascending process of the palatine bone (posterior maxillary sinus wall) in addition to skeletonization of the descending palatine artery and nerve (distal branch of V2) along the medial and posterior aspect of the medial maxillectomy. In this process, the sphenopalatine foramen is unroofed (Fig. 1). Recognizing that the anterior half of the PPF contains distal branches of the internal maxillary artery (IMA), the periosteal sheath of the PPF is sharply incised. After reducing the fatty tissue of the PPF with bipolar cautery, the sphenopalatine artery is identified and clipped, allowing mobilization of the descending palatine artery and remaining IMA branches laterally and inferiorly away from the surgical trajectory. Incision of the PPF's posterior periosteal sheath permits identification of the anterior junction of the medial and lateral pterygoid plates and the infratemporal fossa. Prior to making this posterior incision, key distal branches of V2 should be identified, including the descending palatine and infraorbital nerves. The incision is placed just lateral to these structures to avoid neural injury and allow for access into the infratemporal fossa.

\section{Transpterygoid/Medial Infratemporal Fossa Dissection}

After skeletonizing and mobilizing the descending palatine nerve, $\mathrm{V} 2$ at the foramen rotundum is identified at the superior-most aspect of the pterygoid wedge (the anterior junction of the medial and lateral pterygoid plates). Within the infratemporal fossa laterally, the inferior head of the lateral pterygoid muscle is detached from its named pterygoid plate while leaving the superior head untouched at the middle cranial fossa floor. The pterygoid plates are drilled away in their entirety. Removal of the pterygoid plates is considered complete once V2 is fully skeletonized from the foramen rotundum toward Meckel's cave posteriorly and V3 has been skeletonized at the foramen ovale extending superomedially to Meckel's cave (Fig. 2). The attachment of the medial pterygoid muscle to the lateral aspect of the medial pterygoid plate marks the posterior endpoint of the bone resection in the same axial plane as the eustachian tube. Dissection along the middle fossa floor stops medial to the foramen spinosum and does not extend posteriorly beyond V3 (given the close posterior proximity of the horizontal petrous carotid artery) until completion of subsequent steps.

\section{Transclival Dissection}

Exposure of the ventral mid and inferior clivus requires an inverted U-shaped incision through the mucosa and the longus capitis muscles along the posterior nasopharynx. For management of petroclival chondrosarcomas, a limited ipsilateral mid and lower clivectomy is performed exposing normal posterior fossa dura posterior to the torus tubarius. Given the scenario for which this technique is described, this bone is often normal and requires hemostasis of rich osseous venous channels.

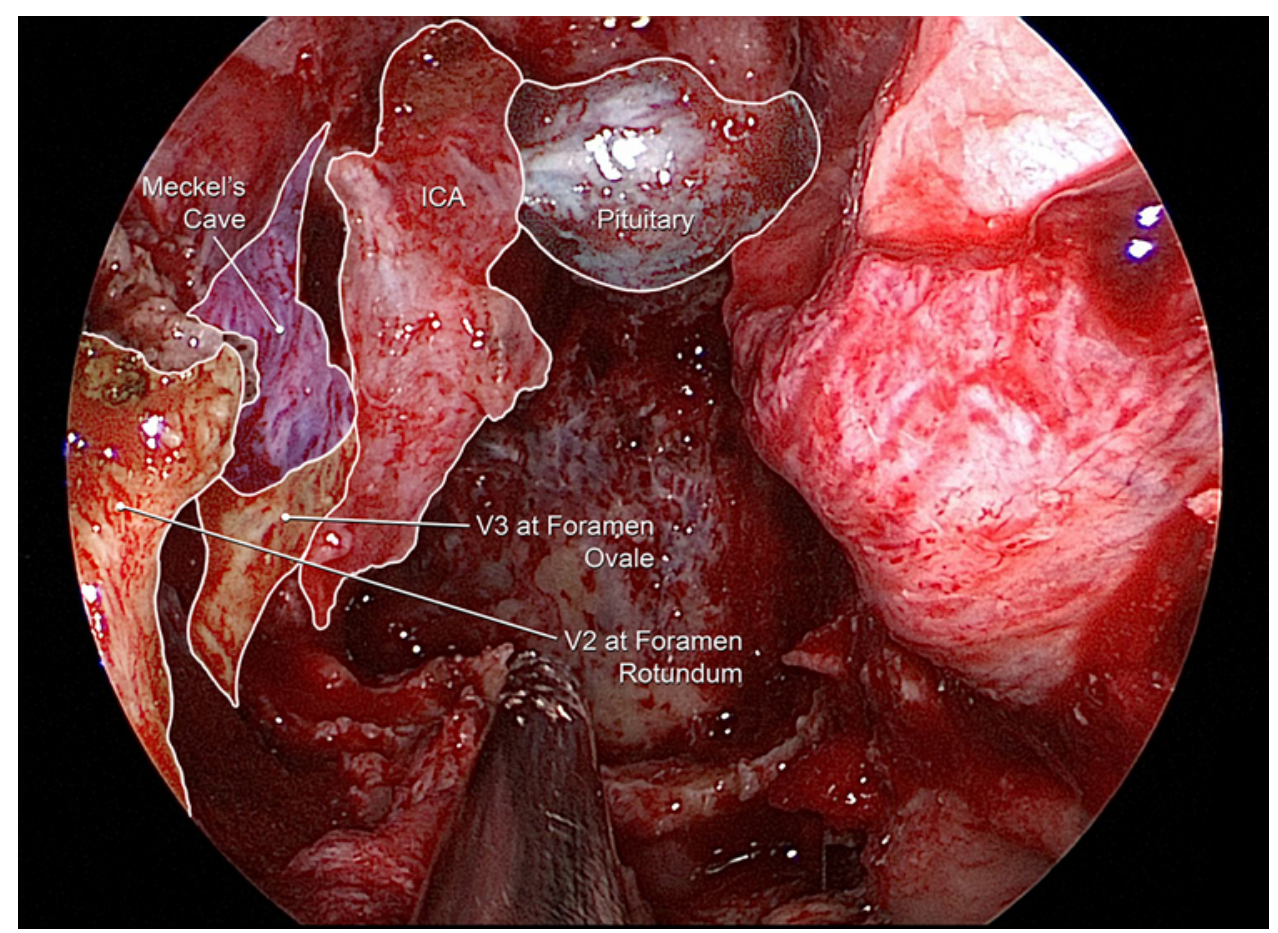

FIG. 2. Transpterygoid dissection. At the completion of drilling the medial/lateral pterygoid plates, the following structures are identified: V2, V3, Meckel's cave, lateral pterygoid muscle, medial pterygoid muscle, and ICA (cavernous, paraclival, and laceral segments). Images are depicted for an approach to the right petroclival synchondrosis. Figure is available in color online only. 


\section{Carotid Artery Dissection}

The paraclival and laceral segments of the carotid artery are circumferentially skeletonized using the vidian nerve as a guide to their junction along with V3 as a marker of the horizontal petrous segment of the carotid artery. The carotid is exposed using a high-speed self-irrigating diamond drill and curettes, if necessary. A micro-Doppler and neuronavigation may be useful in poorly pneumatized sphenoid sinuses. In this process, the thin bony plate between the carotid artery and superior surface of the eustachian tube is resected and the fibrocartilagenous tissue along the inferior half of foramen lacerum is exposed (Fig. 3). The vidian artery, when present, must be carefully ligated to mobilize the paraclival second genu of the internal carotid artery (ICA) superiorly and laterally. If additional exposure of the inferior aspect of Kawase's triangle is required, the paraclival/cavernous carotid artery can be further mobilized superolaterally by performing an anterior-posterior dural incision along the medial cavernous sinus wall. Furthermore, if circumferential control of the carotid artery is required, then dural incisions within Meckel's cave (extending from the lateral aspect of the paraclival carotid artery toward the superior aspect of the laceral segment of the carotid artery) can be performed. Lastly, if extensive dissection around the vertical petrous or parapharyngeal ICA is anticipated, proximal control is obtained via a small transcervical incision with placement of a vessel loop along the ICA at the bifurcation.

\section{Eustachian Tube Dissection}

The superior half of the medial pterygoid muscle is detached to expose the eustachian tube and associated musculature. The tensor veli palitni muscle is detached from the lateral surface of the eustachian tube (Fig. 4). The levator veli palitni is now exposed inferiorly, and is similarly detached to complete exposure of the cartilaginous portion of the eustachian tube. The only remaining attachment of the eustachian tube is to the inferior half of the foramen lacerum. To further mobilize the eustachian tube, this fibrocartilaginous tissue at the foramen is sharply incised from medial to lateral while mobilizing the ICA superiorly. An incision through the lateral-most aspect of the exposed eustachian tube is made to remove the medial cartilaginous portion of the eustachian tube and "unlock" access to the entire petroclival synchondrosis, petrous apex, and medial jugular foramen. This step unifies the entire surgical field, facilitating direct access to the entire petroclival synchondrosis. The trajectory afforded by this approach is medial to the parapharyngeal ICA, which lies just posterior and medial to the medial pterygoid and tensor veli palitini muscles.

\section{Resection and Reconstruction}

An anatomical resection of the bony compartment along with removal of any extracompartmental disease (i.e., subdural disease or disease anteriorly into the longus capitis muscle) is attempted (Fig. 5). The petroclival synchondrosis, adjacent petrous bone, and clivus are drilled back to normal bone or posterior fossa dura, up to the carotid artery, medially toward the jugular foramen, and
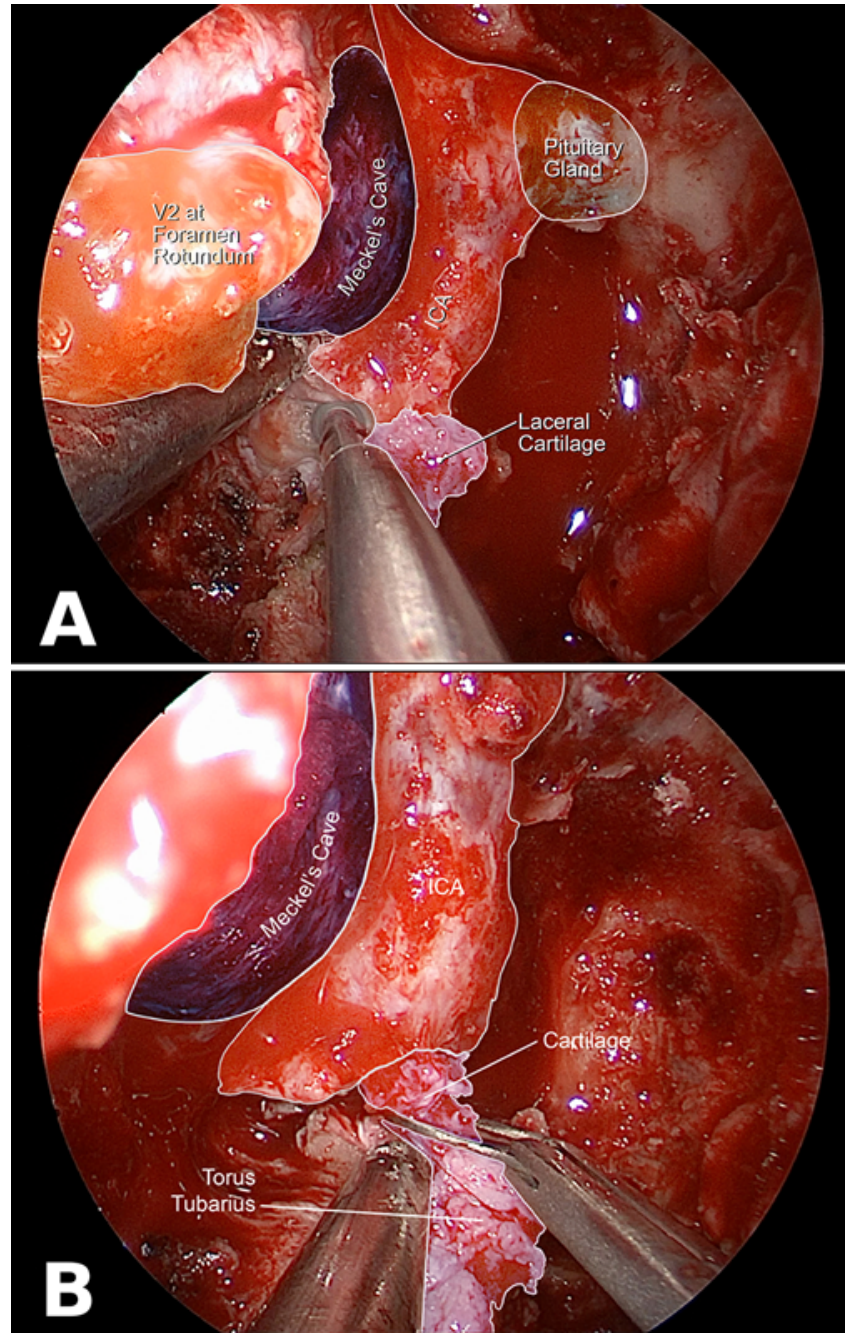

FIG. 3. Resection of laceral cartilage. The foramen lacerum can conceptually be divided into a superior half, containing the laceral segment of the ICA, and an inferior half, containing fibrocartilaginous tissue. A: The foramen lacerum is opened to facilitate safe dissection between the ICA and eustachian tube. B: Once isolated, the fibrocartilaginous tissue is sharply transected. This maneuver not only aids in isolating the eustachian tube but also permits upward mobilization of the laceral ICA to access Kawase's triangle. Images are depicted for an approach to the right petroclival synchondrosis. Figure is available in color online only.

inferiorly to expose the length of the hypoglossal canal. The jugular tubercle is exposed and resected as laterally as safely feasible. Any ventral disease extension into the longus capitis can be accessed via this approach and resected as long as it is not adherent to the lower cranial nerves (CNs). Subdural disease extension is resected and the dural reconstruction is performed in a multilayer fashion. It is important to note that, beyond prevention of a CSF fistula, a vascularized reconstruction is necessary for carotid artery coverage and promotion of skull base healing prior to initiation of adjuvant therapy (if indicated). This is typically augmented by application of a dural sealant. A rigid buttress is not used. A lumbar drain is used postoperatively in cases in which a CSF fistula is anticipated or encountered. 


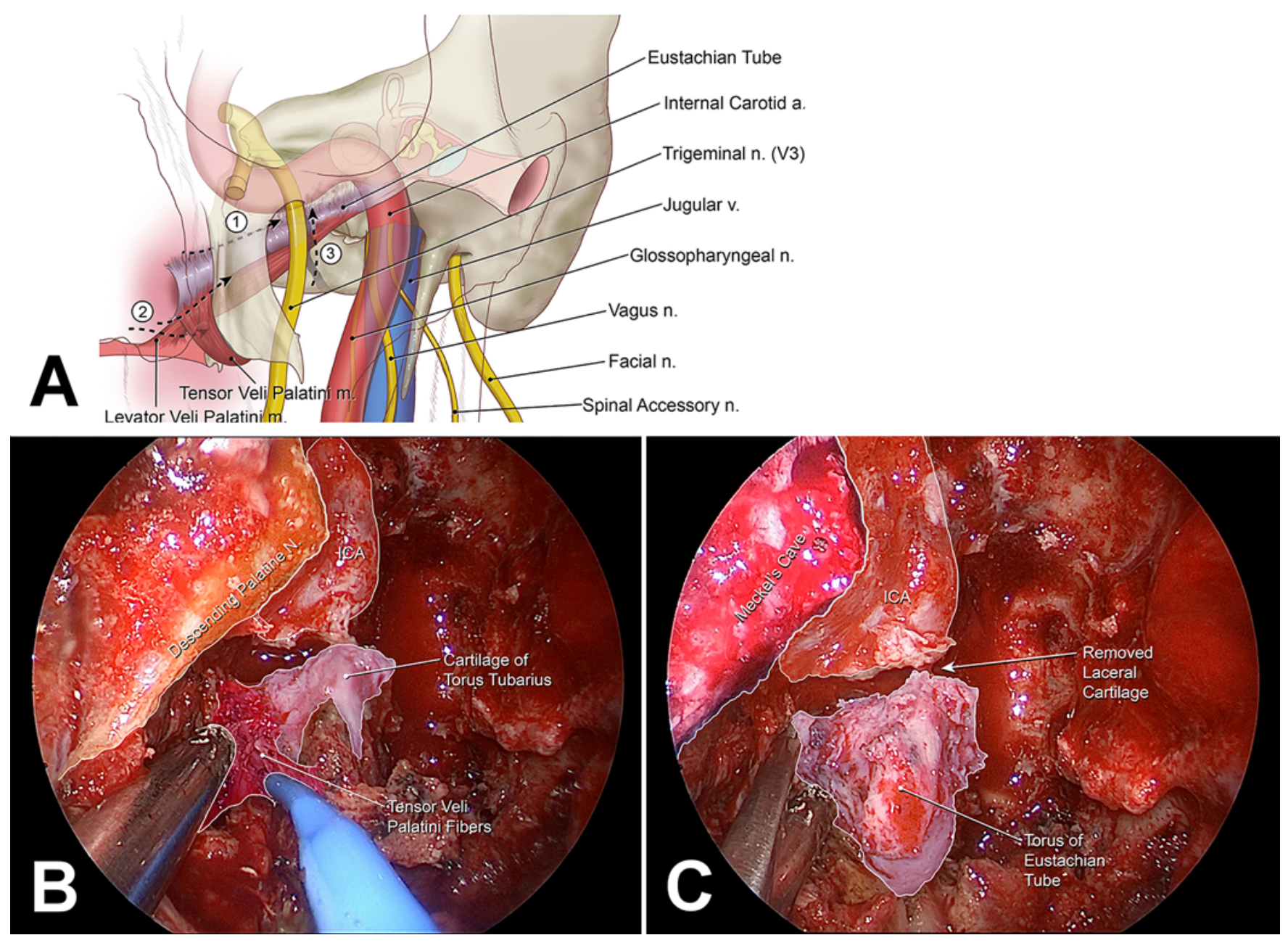

FIG. 4. Eustachian tube dissection. A: Anatomical structures and steps relevant to eustachian tube dissection are highlighted. Step 1, dissection along fibrocartilaginous tissue of the foramen lacerum. B: Step 2, dissection of tensor and levator veli palitini from the eustachian tube. C: Step 3, lateral incision through the eustachian tube while remaining cognizant of parapharyngeal ICA location. v. = vein. Copyright Shaan M. Raza (panel A). Published with permission. Figure is available in color online only.

\section{Surgical Results}

Patient characteristics are summarized in Table 1. The study cohort consisted of 3 males and 2 females, with a median age of 50 years. Within the bony skull base, 4 of the 5 tumors had superior extension above the horizontal petrous ICA, which was managed by mobilizing the horizontal petrous carotid artery superiorly. While all lesions had invasion of the clivus, none of the tumors had midline clival (medial to the plane of the paraclival ICA) or sphenoid sinus extension. All tumors had extracompartmental extension posteriorly into the epidural space and 3 had subdural disease extension. Three patients had ventral extension into the longus capitis muscle and 1 patient had subtle extension beyond the jugular foramen into the carotid sheath. This patient underwent a subtotal (>95\%) resection with residual left along the lower CNs exiting the jugular foramen (Fig. 6). Gross-total resection was achieved in the remaining 4 patients. Postoperative clinic outcomes at 3 months are presented in Table 2. One patient had preoperative V2 numbness, which improved postoperatively. Two patients with complete CN VI defi- cits preoperatively had no change postoperatively; however, 2 patients with partial CN VI deficits preoperatively had improvement, but not resolution, postoperatively. Four of 5 patients presented with some degree of conductive hearing loss preoperatively; with the eustachian tube resection, this was corrected postoperatively in all patients with placement of a tympanostomy tube after completion of adjuvant radiotherapy. Two patients with preoperative CN IX-XI deficits showed improvement postoperatively. Preoperative hypoglossal weakness improved in 1 patient and remained stable in another. While palatal numbness was noted in all patients immediately postoperatively due to intraoperative mobilization of the descending palatine nerve, this went away in all patients by 3 months following surgery. No other new $\mathrm{CN}$ deficits or 30-day surgical complications occurred.

Median clinical follow-up of 19 months (range 6-30 months) was available postoperatively. Consistent with a multimodality treatment protocol we have previously reported, all patients with pathology consistent with a Grade 2 chondrosarcoma (patients 1-4) received postoperative 

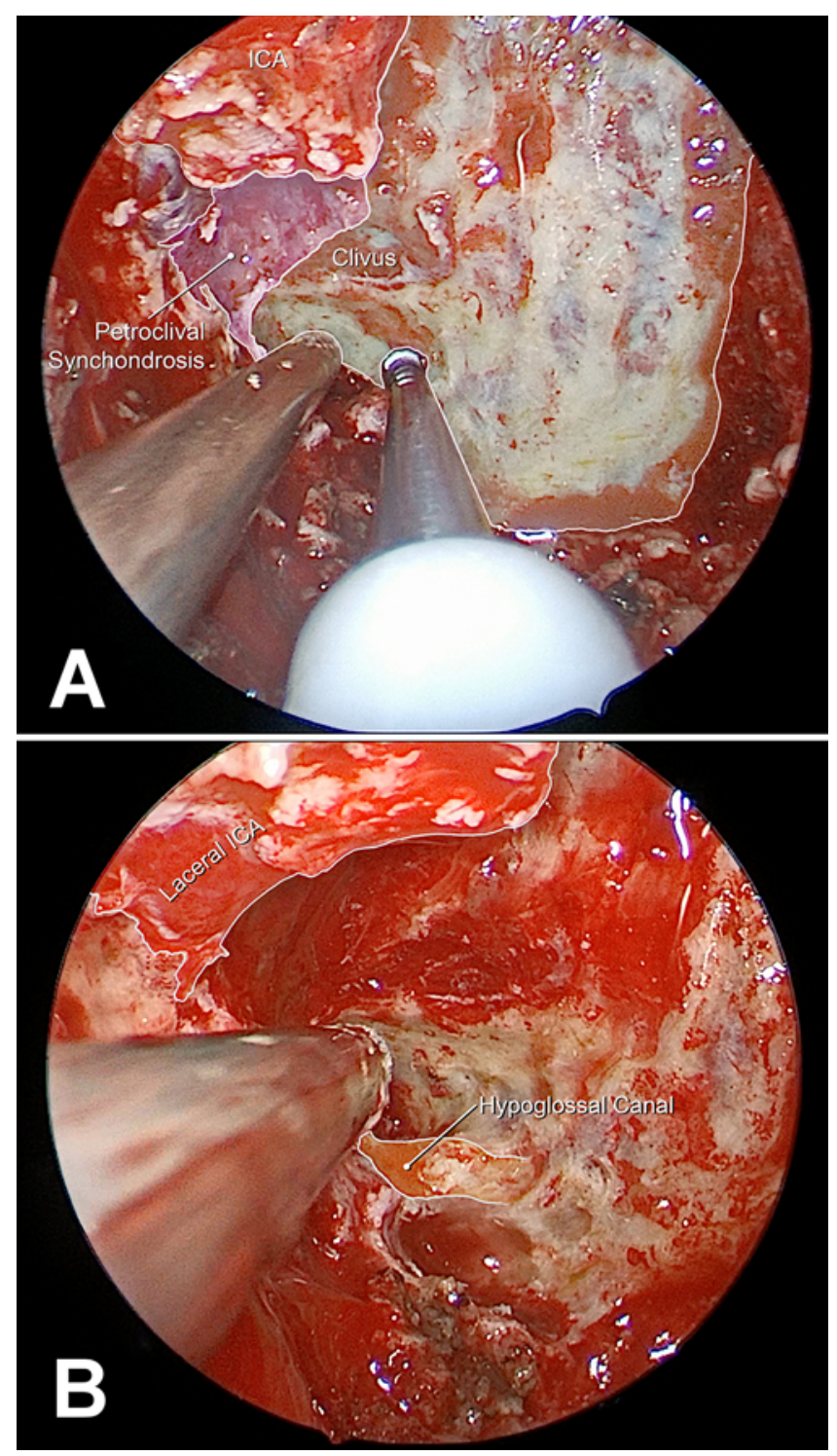

FIG. 5. Intraoperative exposure of the petroclival junction. The previously described dissection steps facilitate safe drilling of any diseased bone involving the petrous temporal bone and clivus. Images are depicted for an approach to the right petroclival synchondrosis. Figure is available in color online only. proton radiation therapy $(66-70 \mathrm{~Gy}) .{ }^{18}$ One patient with a Grade 1 chondrosarcoma underwent serial observation. No patient demonstrated evidence of disease recurrence or progression through the most recent follow-up evaluation.

\section{Discussion}

Surgery, within the context of a histology-specific multimodal treatment plan,,$^{18}$ is the cornerstone of management of chondrosarcomas ${ }^{3,16,18,19,23}$ at all anatomical sites. Several studies have demonstrated that achieving a gross-total resection (including all invaded bone in addition to extracompartmental extension outside of the bony skull base) results in improved local control rates for all histological variants. Our previous work has demonstrated that tumor site of origin dictates surgical strategies necessary to achieve a maximal resection in chondrosarcomas. ${ }^{17}$ Extending from the foramen lacerum to the jugular foramen, the petroclival synchondrosis poses a surgical challenge in achieving an oncological resection. In our previous report, petroclival tumors had the lowest rates of resection. While numerous endoscopic and open approaches have been reported in the literature and used in our own institutional experience, the endoscopic endonasal transpterygoid transnasopharyngeal approach reported here has yielded an improved combination of resection rates and neurological outcomes.

The epicenter for petroclival chondrosarcomas is entirely inferior to the horizontal petrous carotid artery. Lateral access to this area is limited by the jugular bulb and CNs VII-XII. Cranial base approaches to this region have primarily relied on "open" transcochlear, anterior petrosal, or subtemporal-infratemporal fossa approaches. 1,17,20,21 These approaches are unified in their inability to safely access medial bone disease extension into the clivus, low petroclival synchondrosis (medial to the jugular bulb), and longus capitis/posterior nasopharynx, despite extensive maneuvers such as facial nerve mobilization. The limitations of employing these surgical strategies are reflected in the larger lateral skull base series to date, which report gross-total resection rates ranging between $27 \%$ and $62 \%$.

Several reports have explored the role of endoscopic transclival/transpterygoid approaches for petroclival pathology. The common surgical access for petroclival lesions has relied on a transclival window resulting in higher resection rates relative to lateral approaches. ${ }^{13,14}$ Unfortunately, this medial to lateral trajectory via the cli-

TABLE 1. Patients treated with reported surgical technique

\begin{tabular}{|c|c|c|c|c|c|c|c|c|c|c|c|}
\hline \multirow[b]{2}{*}{$\begin{array}{l}\text { Pt } \\
\text { No. }\end{array}$} & \multirow[b]{2}{*}{$\begin{array}{l}\text { Histology Subtype/ } \\
\text { Grade }\end{array}$} & \multicolumn{4}{|c|}{ Bony Skull Base Involvement } & \multicolumn{5}{|c|}{ Extracompartmental Extension } & \multirow[b]{2}{*}{$\begin{array}{l}\text { Extent of } \\
\text { Resection }\end{array}$} \\
\hline & & $\begin{array}{l}\text { Petrous Bone: } \\
\text { Infrapetrous }\end{array}$ & $\begin{array}{l}\text { Petrous Bone: } \\
\text { Suprapetrous }\end{array}$ & $\begin{array}{l}\text { Jugular } \\
\text { Foramen }\end{array}$ & $\begin{array}{l}\text { Midline } \\
\text { Clivus }\end{array}$ & $\begin{array}{l}\text { Epidural } \\
\text { Disease }\end{array}$ & $\begin{array}{l}\text { Subdural } \\
\text { Disease }\end{array}$ & $\begin{array}{c}\text { Cavernous } \\
\text { Sinus/Meckel's } \\
\text { Cave }\end{array}$ & $\begin{array}{l}\text { Longus } \\
\text { Capitis }\end{array}$ & $\begin{array}{l}\text { Carotid } \\
\text { Sheath }\end{array}$ & \\
\hline 1 & Conventional Grade 2 & Yes & No & No & No & Yes & Yes & No & No & No & GTR \\
\hline 2 & Conventional Grade 2 & Yes & Yes & Yes & No & Yes & Yes & Yes & Yes & No & GTR \\
\hline 3 & Conventional Grade 2 & Yes & Yes & No & No & Yes & No & Yes & Yes & No & GTR \\
\hline 4 & Conventional Grade 2 & Yes & Yes & Yes & No & Yes & Yes & No & Yes & Yes & STR \\
\hline 5 & Conventional Grade 1 & Yes & Yes & No & No & Yes & No & Yes & No & No & GTR \\
\hline
\end{tabular}

GTR = gross-total resection; $\mathrm{Pt}=$ patient; $\mathrm{STR}=$ subtotal resection . 


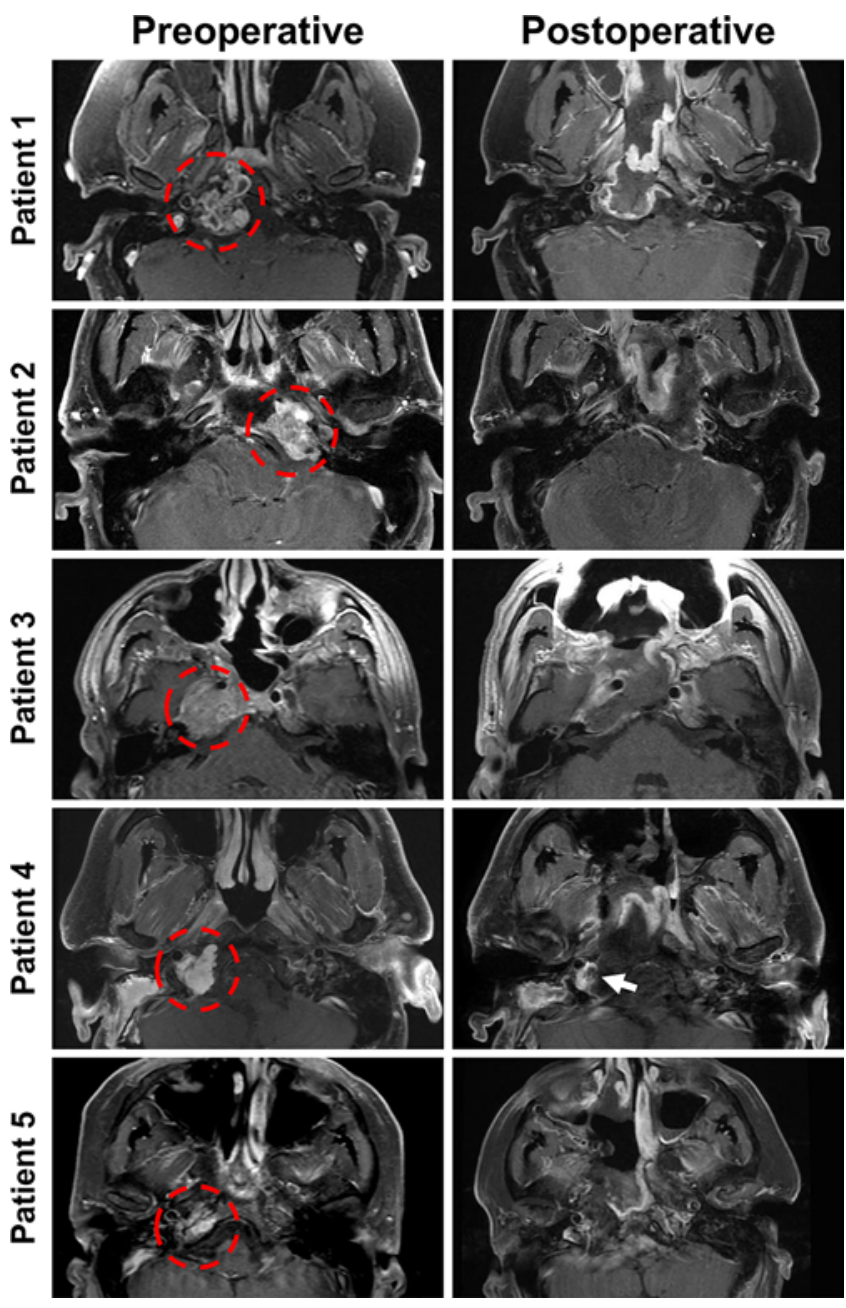

FIG. 6. Pre- and postoperative petroclival chondrosarcomas resected via an endoscopic endonasal transpterygoid approach. Left column: Preoperative axial T1-weighted MRI with contrast demonstrates petroclival chondrosarcomas without medial extension (dashed circles). Right column: Postoperative axial imaging demonstrates gross-total resection in all patients, except patient 4 (subtotal resection, arrow indicates residual tumor). Figure is available in color online only.

vus provides limited lateral access to the jugular foramen. To further enhance access, endoscopic transpterygoid approaches with a translaceral corridor (between the laceral segment of the carotid artery and eustachian tube) have also been reported. ${ }^{22}$ This corridor, however, only permits an intralesional resection without the ability to drill out the invaded petroclival junction with the eustachian tube and carotid artery serving as barriers. Additionally, the reported strategies thus far do not provide an ability to address ventral extension into the longus capitis muscle.

By using a limited endoscopic nasopharyngectomy by dissecting the eustachian tube, ${ }^{2,9}$ the approach reported here provides a single-stage solution to directly accessing the entire petroclival synchondrosis, lateral cavernous sinus/Meckel's cave, posterior fossa, ventral soft tissue, and

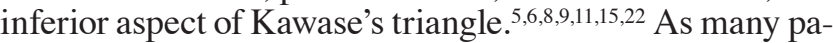
tients present with or ultimately develop conductive hearing loss as a result of treatment (regardless of approach), this approach sacrifices the eustachian tube to maximize resection. Relative to the open and alternative endoscopic approaches, this avoids the need for facial nerve mobilization and provides direct access to bone disease without relying on medial disease extension. While the eustachian tube can theoretically be mobilized via detachment from the skull base, its rigidity limits safe lateral access to the jugular foramen. Medial resection of the torus tubarius facilitates safe, direct, and lateral access.

The endoscopic endonasal transpterygoid transnasopharyngeal approach has limitations. As previously reported in other anatomical studies, access to the superior aspect of the petrous apex and middle fossa is limited via this approach; disease extension superior to the horizontal petrous ICA necessitates an anterior petrosal approach. Another anatomical consideration is the limited access to the carotid sheath and parapharyngeal space necessitating a transcervical approach. Furthermore, the described approach requires a vidian neurectomy, which can produce complications (i.e., corneal ulceration) in patients with preexisting V1 neuropathy. Additionally, the risk of permanent palatal numbness must be considered in counseling patients for future dental surveillance.

\section{Conclusions}

Due to their sheltered site of origin, petroclival chondrosarcomas pose several anatomical challenges in achieving an optimal resection. Building on the strengths of previously described approaches, we report our surgical technique that has, in our opinion, provided for superior extent of resection and improved neurological outcomes relative

TABLE 2. Postoperative outcomes at 3 months

\begin{tabular}{|c|c|c|c|c|c|c|c|c|c|c|}
\hline \multirow{2}{*}{$\begin{array}{l}\text { Pt } \\
\text { No. }\end{array}$} & \multicolumn{2}{|c|}{ CN V } & \multicolumn{2}{|c|}{ CN VI } & \multicolumn{2}{|c|}{ CN IX-XI } & \multicolumn{2}{|c|}{ CN XII } & \multicolumn{2}{|c|}{ Conductive Hearing Loss } \\
\hline & Preop & Postop* & Preop & Postop & Preop & Postop & Preop & Postop & Preop & Postop† \\
\hline 1 & None & None & Present & Stable & None & None & None & None & Present & Improved \\
\hline 2 & None & None & None & None & Present & Improved & None & None & Present & Improved \\
\hline 3 & Present & Improved & Present & Stable & None & None & None & None & Absent & Stable \\
\hline 4 & None & None & Present & Improved & Present & Improved & Present & Stable & Present & Improved \\
\hline 5 & None & None & Present & Improved & None & None & Present & Improved & Present & Improved \\
\hline
\end{tabular}

* Describes temporary palatal numbness due to mobilization of the descending palatine nerve.

† Conductive hearing defects either preoperatively or postoperatively corrected with placement of tympanostomy tube. 
to the spectrum of open approaches used in our practice. This technique should be employed as the primary surgical strategy for petroclival chondrosarcomas, recognizing the need for supplementary lateral approaches depending on superior and lateral tumor extent. Long-term follow-up will be required to assess local control rates and patterns of recurrence.

\section{Acknowledgments}

We thank David Aten for assistance in preparation of figures and illustrations for this manuscript.

\section{References}

1. Al-Mefty O, Fox JL, Rifai A, Smith RR: A combined infratemporal and posterior fossa approach for the removal of giant glomus tumors and chondrosarcomas. Surg Neurol 28:423-431, 1987

2. Al-Sheibani S, Zanation AM, Carrau RL, Prevedello DM, Prokopakis EP, McLaughlin N, et al: Endoscopic endonasal transpterygoid nasopharyngectomy. Laryngoscope 121:2081-2089, 2011

3. Crockard HA, Cheeseman A, Steel T, Revesz T, Holton JL, Plowman N, et al: A multidisciplinary team approach to skull base chondrosarcomas. J Neurosurg 95:184-189, 2001

4. Evans HL, Ayala AG, Romsdahl MM: Prognostic factors in chondrosarcoma of bone: a clinicopathologic analysis with emphasis on histologic grading. Cancer 40:818-831, 1977

5. Fortes FS, Sennes LU, Carrau RL, Brito R, Ribas GC, Yasuda A, et al: Endoscopic anatomy of the pterygopalatine fossa and the transpterygoid approach: development of a surgical instruction model. Laryngoscope 118:44-49, 2008

6. Freeman JL, Sampath R, Quattlebaum SC, Casey MA, Folzenlogen ZA, Ramakrishnan VR, et al: Expanding the endoscopic transpterygoid corridor to the petroclival region: anatomical study and volumetric comparative analysis. J Neurosurg 128: 1855-1864, 2018

7. Gay E, Sekhar LN, Rubinstein E, Wright DC, Sen C, Janecka IP, et al: Chordomas and chondrosarcomas of the cranial base: results and follow-up of 60 patients. Neurosurgery 36:887-897, 1995

8. Hofstetter CP, Singh A, Anand VK, Kacker A, Schwartz TH: The endoscopic, endonasal, transmaxillary transpterygoid approach to the pterygopalatine fossa, infratemporal fossa, petrous apex, and the Meckel cave. J Neurosurg 113:967-974, 2010

9. Hosseini SM, McLaughlin N, Carrau RL, Otto B, Prevedello DM, Solares CA, et al: Endoscopic transpterygoid nasopharyngectomy: correlation of surgical anatomy with multiplanar CT. Head Neck 35:704-714, 2013

10. Jacquesson T, Berhouma M, Tringali S, Simon E, Jouanneau $\mathrm{E}$ : Which routes for petroclival tumors? A comparison between the anterior expanded endoscopic endonasal approach and lateral or posterior routes. World Neurosurg 83:929_ 936, 2015

11. Kasemsiri P, Solares CA, Carrau RL, Prosser JD, Prevedello DM, Otto BA, et al: Endoscopic endonasal transpterygoid approaches: anatomical landmarks for planning the surgical corridor. Laryngoscope 123:811-815, 2013

12. Kim MJ, Cho KJ, Ayala AG, Ro JY: Chondrosarcoma: with updates on molecular genetics. Sarcoma 2011:405437, 2011

13. Mesquita Filho PM, Ditzel Filho LF, Prevedello DM, Martinez CA, Fiore ME, Dolci RL, et al: Endoscopic endonasal surgical management of chondrosarcomas with cerebellopontine angle extension. Neurosurg Focus 37(4):E13, 2014

14. Moussazadeh N, Kulwin C, Anand VK, Ting JY, Gamss C, Iorgulescu JB, et al: Endoscopic endonasal resection of skull base chondrosarcomas: technique and early results. J Neurosurg 122:735-742, 2015

15. Muto J, Prevedello DM, Ditzel Filho LF, Tang IP, Oyama K, Kerr EE, et al: Comparative analysis of the anterior transpetrosal approach with the endoscopic endonasal approach to the petroclival region. J Neurosurg 125:1171-1186, 2016

16. Oghalai JS, Buxbaum JL, Jackler RK, McDermott MW: Skull base chondrosarcoma originating from the petroclival junction. Otol Neurotol 26:1052-1060, 2005

17. Raza SM, Gidley PW, Kupferman ME, Hanna EY, Su SY, DeMonte F: Site-specific considerations in the surgical management of skull base chondrosarcomas. Oper Neurosurg (Hagerstown) 14:611-619, 2018

18. Raza SM, Gidley PW, Meis JM, Grosshans DR, Bell D, DeMonte F: Multimodality treatment of skull base chondrosarcomas: the role of histology specific treatment protocols. Neurosurgery 81:520-530, 2017

19. Samii A, Gerganov V, Herold C, Gharabaghi A, Hayashi N, Samii M: Surgical treatment of skull base chondrosarcomas. Neurosurg Rev 32:67-75, 2009

20. Sekhar LN, Pranatartiharan R, Chanda A, Wright DC: Chordomas and chondrosarcomas of the skull base: results and complications of surgical management. Neurosurg Focus 10(3):E2, 2001

21. Sekhar LN, Schramm VL Jr, Jones NF: Subtemporal-preauricular infratemporal fossa approach to large lateral and posterior cranial base neoplasms. J Neurosurg 67:488-499, 1987

22. Taniguchi M, Akutsu N, Mizukawa K, Kohta M, Kimura H, Kohmura E: Endoscopic endonasal translacerum approach to the inferior petrous apex. J Neurosurg 124:1032-1038, 2016

23. Tzortzidis F, Elahi F, Wright DC, Temkin N, Natarajan SK, Sekhar LN: Patient outcome at long-term follow-up after aggressive microsurgical resection of cranial base chondrosarcomas. Neurosurgery 58:1090-1098, 2006

24. Vaz-Guimaraes F, Fernandez-Miranda JC, Koutourousiou M, Hamilton RL, Wang EW, Snyderman CH, et al: Endoscopic endonasal surgery for cranial base chondrosarcomas. Oper Neurosurg (Hagerstown) 13:421-434, 2017

25. Wanebo JE, Bristol RE, Porter RR, Coons SW, Spetzler RF: Management of cranial base chondrosarcomas. Neurosurgery 58:249-255, 2006

\section{Disclosures}

The authors report no conflict of interest concerning the materials or methods used in this study or the findings specified in this paper.

\section{Author Contributions}

Conception and design: Raza, DeMonte. Acquisition of data: Raza, DeMonte, Su, Kupferman, Hanna. Analysis and interpretation of data: Raza, Mehta. Drafting the article: Raza, Mehta. Critically revising the article: all authors. Reviewed submitted version of manuscript: all authors. Approved the final version of the manuscript on behalf of all authors: Raza. Study supervision: Raza.

\section{Supplemental Information \\ Videos}

Video 1. https://vimeo.com/265270070.

\section{Correspondence}

Shaan M. Raza: The University of Texas M.D. Anderson Cancer Center, Houston, TX. smraza@mdanderson.org. 